\title{
Postoperative Use of Dopamine Agonist in Controlling the Residual Mass in Non Functioning Pituitary Adenoma
}

\author{
Mohamed Mahmoud1', Ahmad A. Moussa', ${ }^{1,2}$, Ahmad Elsayed Abokresha1, Hazem A. Yousef ${ }^{3}$ \\ ${ }^{1}$ Department of Neurosurgery, Assiut University Hospital, Assiut, Egypt \\ ${ }^{2}$ Department of Neurosurgery, Queen Elizabeth Hospital, Birmingham, UK \\ ${ }^{3}$ Department of Radiology, Assiut University Hospital, Assiut, Egypt \\ Email:msmluxor@yahoo.com,ahmad_a_moussa@yahoo.com, ahabokreshaa@gmail.com,bozaidhazz@yahoo.com
}

How to cite this paper: Mahmoud, M., Moussa, A.A., Abokresha, A.E. and Yousef, H.A. (2020) Postoperative Use of Dopamine Agonist in Controlling the Residual Mass in Non Functioning Pituitary Adenoma. Open Journal of Modern Neurosurgery, 10, 267-274.

https://doi.org/10.4236/ojmn.2020.102029

Received: January 4, 2020

Accepted: April 17, 2020

Published: April 20, 2020

Copyright $\odot 2020$ by author(s) and Scientific Research Publishing Inc. This work is licensed under the Creative Commons Attribution International License (CC BY 4.0).

http://creativecommons.org/licenses/by/4.0/

\begin{abstract}
Background: Non-functioning pituitary adenoma (NFPA) is a challenging tumor. It is usually reached to a large size before it is clinically manifested. Operative interference is the first option in treatment of large NFPA causing compressive manifestations but with frequent postoperative residual masses that is usually required additional treatment. Postoperative radiotherapy carried frequent side effects which open the door for postoperative medical treatment with dopamine agonist (DA) drugs based on the fact that these tumors have a variable amount of dopamine receptors. Lack of randomized, placebo-controlled trials prevents any conclusion on the efficacy of this drug. Its role in controlling postoperative proliferation and decreasing the rate of recurrence of NFPA is still questionable. Objective: Efficacy of bromocriptine (dopamine agonist (DA) drug) in reducing or preventing the re-growth of non-functioning pituitary adenoma NFPA after surgery. Methods: In this study, we examined the outcome of treating NFPA after surgery, with bromocriptine (dopamine agonists drug). This study was a retrospective review of consecutive patients that were treated by the authors at Assiut University Hospital between 2012-2018. All patients had postoperative Bromocriptine in a dose of $2.5 \mathrm{mg}$ twice daily. Results: Thirty two patients were included in this study after they had surgery for NFPA. All patients had a residual mass documented by the immediate post operative MRI. After 6 months of postoperative bromocriptine treatment, and with comparing to immediate post operative images, eleven patients (34\%) had mass reduction, thirteen patients (41\%) of their residual masses remained unchanged and eight patients $(25 \%)$ of the mass showed slight increase in size but not required re-surgery. After two years and throughout the follow up period, seven patients (22\%) (all were
\end{abstract}


males) had complete disappearance of the mass; ten patients (31\%) had more reduction of the size of the mass (two of them were males) and four patients (13\%) of the mass remained unchanged (none of them were males) and eleven patients (34\%) had increase of the mass and they required re-surgery (two of them were males). Conclusion: Bromocriptine (DA drug) can play a role in reducing the size or preventing the re-growth of non-functioning pituitary adenoma after surgical debulking. Males showed noticeable response comparing to females. Its regular use might limit the need for surgery in this type of tumor. Further studies with large number of patients are highly recommended.

\section{Keywords}

Dopamine Agonists (DA), Non-Functioning Pituitary Adenoma (NFPA)

\section{Introduction}

Non-functioning pituitary adenomas (NFPAs) account of 25\% of all pituitary adenomas [1]. Most of these tumors represent themselves as macroadenoma and have been delayed in diagnosis until they reached to size enough to produce compressive symptoms like visual affection, headache and/or hypogonadism [2]. The first line of treatment of these tumors is surgical excision [3]. However, due to the nature of growth and extension of these tumor, surgery is usually failed to totally remove all neoplastic tissues, and residual masses is a common postoperative image finding that can re-grow during follow up period in most of patients [4]. Postoperative radiotherapy is still controversial, and is not usually preferred due to its potential side effects that include hypopituitarism, neurocognitive dysfunction and cerebrovascular disease besides the rare occurrence of postradiation secondary intracranial tumor [5] [6]. However, by immunocytochemistry, most of these tumors are glycoprotein producing, and less commonly are non-functioning somatotroph, lactotroph or corticotroph adenomas. A proportion of NFPA secretes small amounts of FSH and LH and/or their a- and b-subunits either in vitro or in vivo [3]. Different subtypes of dopamine and somatostatin receptors were found in a variable amount in most of NFPA cell membranes. Based on this point, dopamine agonists (DA) and somatostatin analogues (SSA) may have a role in the treatment of NFPA. However, except for some case reports, the results of medical treatment with DA were disappointing [7]. The existence of a functional interaction between dopamine and somatostatin receptors has opened a new perspective of medical treatment for NFPA [8]. Bromocriptine was discovered by scientists at Sandoz in 1965 and was first published in 1968. It was first marketed under the brand name Parlodel [9]. Bromocriptine is a dopamine agonist (DA) and is well established as first line therapy for prolactinomas. This is thought to be due to high levels of dopamine receptors in prolactinoma [2]. Patients with NFPA typically lack serum markers reflecting 
tumor proliferation, so treatment efficacy is based on tumor size assessment by Magnetic Resonance Imaging (MRI) and Computer Tomography (CT) at regular intervals [10]. The aim of this work is to study the efficacy of bromocriptine (dopamine agonist (DA) drug) in reducing or preventing the re-growth of non-functioning pituitary adenoma NFPA after surgery.

\section{Materials and Methods}

This is a retrospective study analyzing data from patients records and scans that were carried out at Assiut university hospital for all cases whom were diagnosed by the authors as having non functioning pituitary macroadenoma between 2012-2018. Inclusion criteria include all patients presented with neurological manifestations related to non functioning pituitary macroadenoma who are fit for surgery. Exclusion criteria include functioning pituitary adenoma, pituitary microadenoma and unfit patients. All patients were treated with surgical debulking of the tumor with decompression of optic nerves followed by prescription of Bromocriptine therapy during the postoperative and follow up period as a trial to control the re-growth of the residual mass. Bromocriptine was administered in a dose of $2.5 \mathrm{mg}$ twice daily. The clinical features and neuro-image of our patients were reviewed to confirm the diagnosis of NFPA and the incidence of re growth of the adenoma after surgery. Clinical and radiological outcome were reviewed over a follow up period of six years.

\section{Results}

Thirty two patients were included in this study. Twenty one patients (66\%) were females and eleven patients (34\%) were males. Their ages ranged from 18 to 65 years with a mean age of 37 .

All of our patient presented with a variable degree of visual filed and/or acuity affection as a main complaint. All of our patient were operated in the department of neurosurgery, Assiut university. Twenty patients had transsphenoidal approach, and twelve patients (with large suprasellar extension) (Figure 1) had right subfrontal approach and debulking of the mass and the assurance of completion of optic nerves decompression. Postoperative course was smooth in twenty three patients. five patients had CSF leak which stopped by conservative treatment in 1 - 2 week, four patients did not recover well and emergent CT scan was done to all of them and showed frontal contusion in three patients whom been treated conservatively and recovered in $5-7$ days and hematoma in the operative bed in the fourth patient that required surgical evacuation, and he regain his conscious level after 3 day but with deterioration of his vision. Twenty two patients (69\%) their vision improved immediately after surgery, seven patients (22\%) remain unchanged, and three patients (9\%) had deterioration of their visions. All of our patients had a residual tumor appeared in the immediate post operative images (Figure 2) and all of them received bromocriptine tablets in a dose of $2.5 \mathrm{mg}$ every 12 hours After 6 months of postoperative bromocriptine 


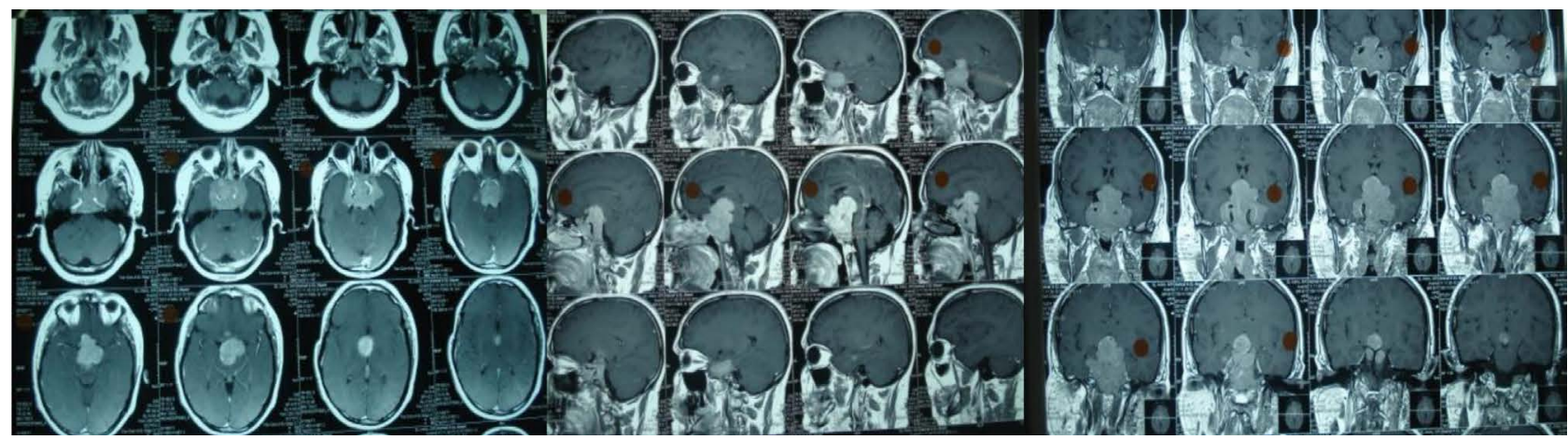

Figure 1. Preoperative MRI brain of a 40 years old male patient with sever visual acuity and field affection, rt subfrontal approach was done and decompression of both optic nerves.

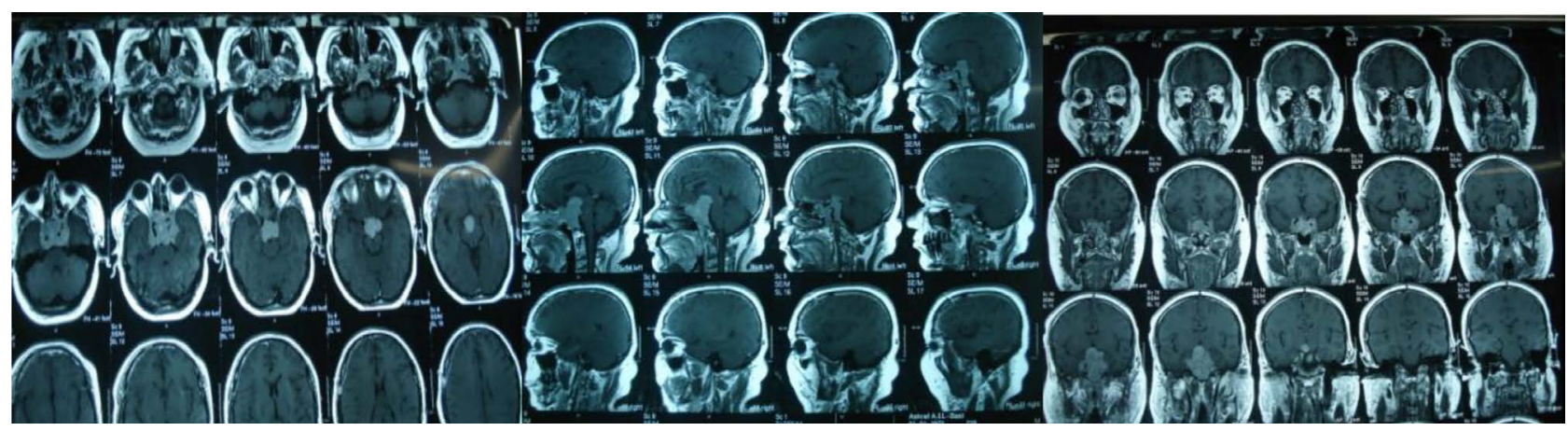

Figure 2. Immediate post operative images of the same patients shows large residual mass.

treatment, and with comparing to the immediate post operative images, eleven patients (34\%) had mass reduction, (Figure 3 ) thirteen patients (41\%) their residual masses remained unchanged and eight patients (25\%) the mass showed slight increase in size but not required re surgery. After two years and throughout the follow up period, seven patients (22\%) (all were males) had complete disappearance of the mass, (Figures 4-6) ten patients (31\%) had more reduction of the size of the mass (two of them were males) and four patients (13\%) the mass remained unchanged (none of them were males) and eleven patients (34\%) had increase of the mass and they required re surgery (two of them were males) (Table 1). Tumor control was achieved in $66 \%$ of the patient (Figure 7) complete disappearance of the mass was observed in $64 \%$ of the males comparing to $0 \%$ in females, total tumor control was $82 \%$ in males comparing to $57 \%$ in females (Figure 8).

\section{Discussion}

Surgery is considered the first option in management of NFPA. however, residual mass is a common postoperative finding in most of those patients due to the fact that the diagnosis is usually delayed and the tumor reached a large size with supra-and para sellar extension [2] All of our patients had a residual tumor in immediate post operative images. Ferrante et al. [11], in studying of 295 patients with NFPA underwent surgery, reported total excision of the mass in only 


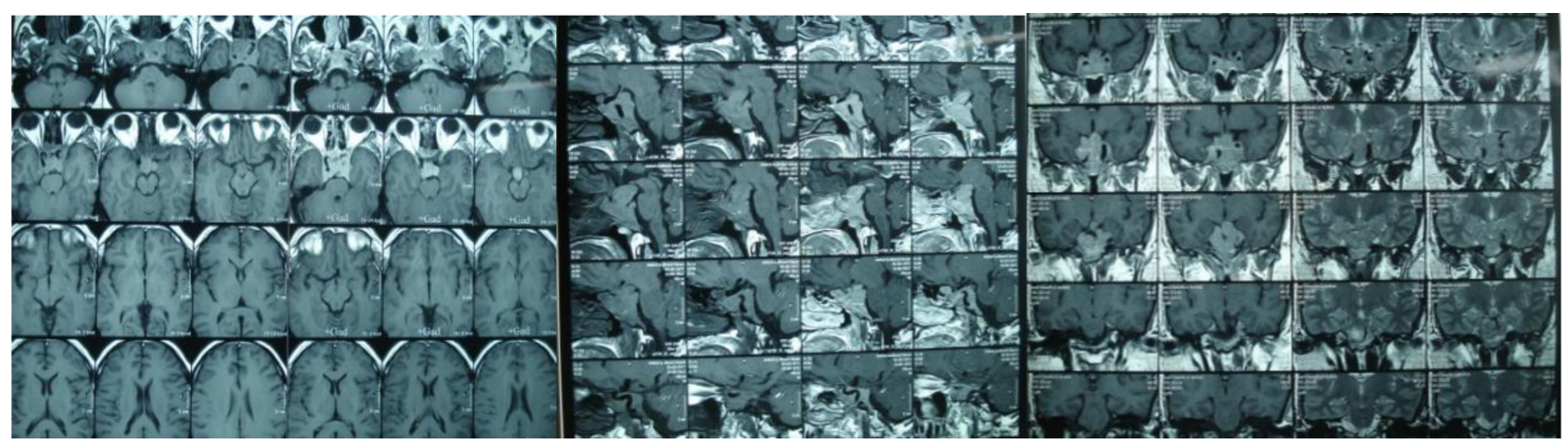

Figure 3. MRI brain of the same patients after 6 months of DA treatment shows reduction of the residual mass.

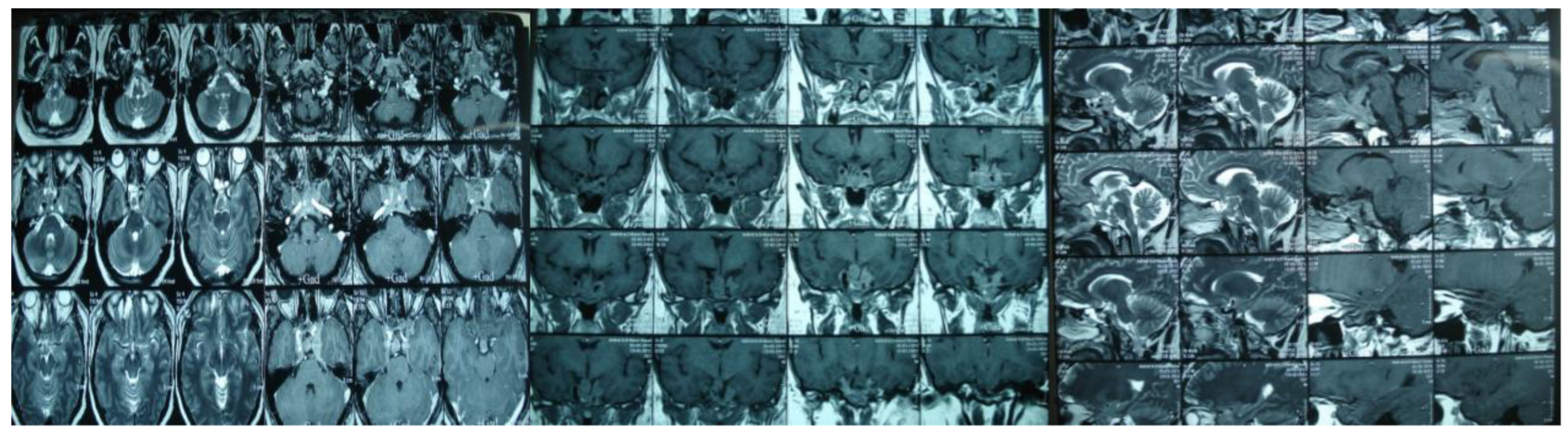

Figure 4. MRI of the same patient after one year medical treatment shows more shrinkage of the mass.

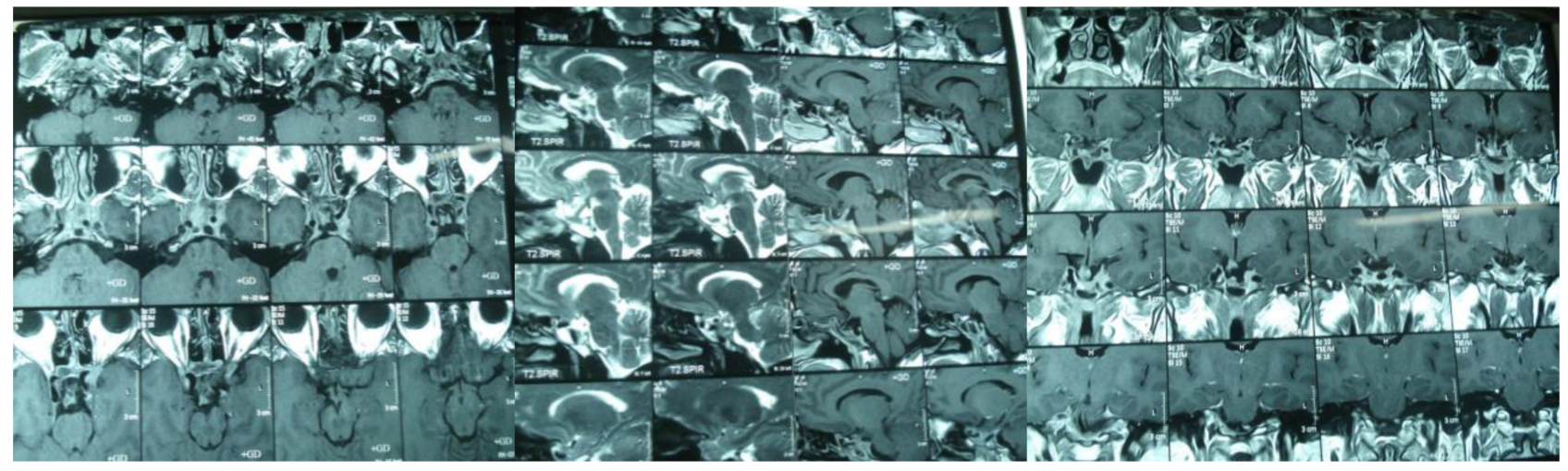

Figure 5. MRI of the same patients after 2 years medical treatment with complete disappearance of the mass.

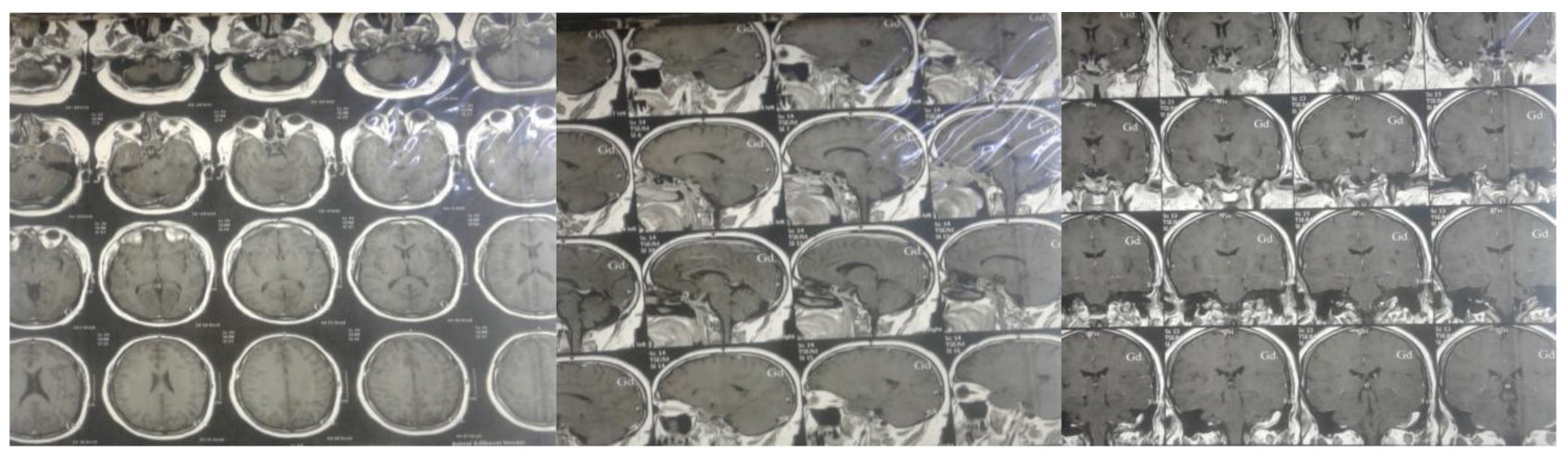

Figure 6. MRI brain of the same patients after 6 years follow up shows no recurrence. 


\section{tumor control}

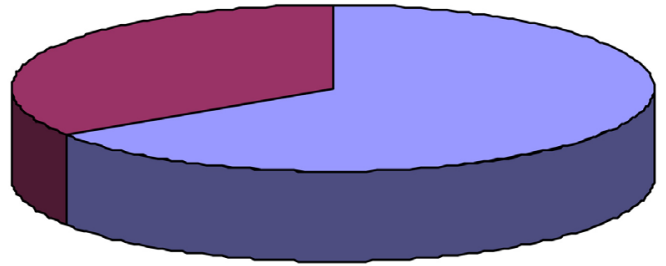

Figure 7. Tumor control was achieved in $66 \%$ of the patient after 6 years.

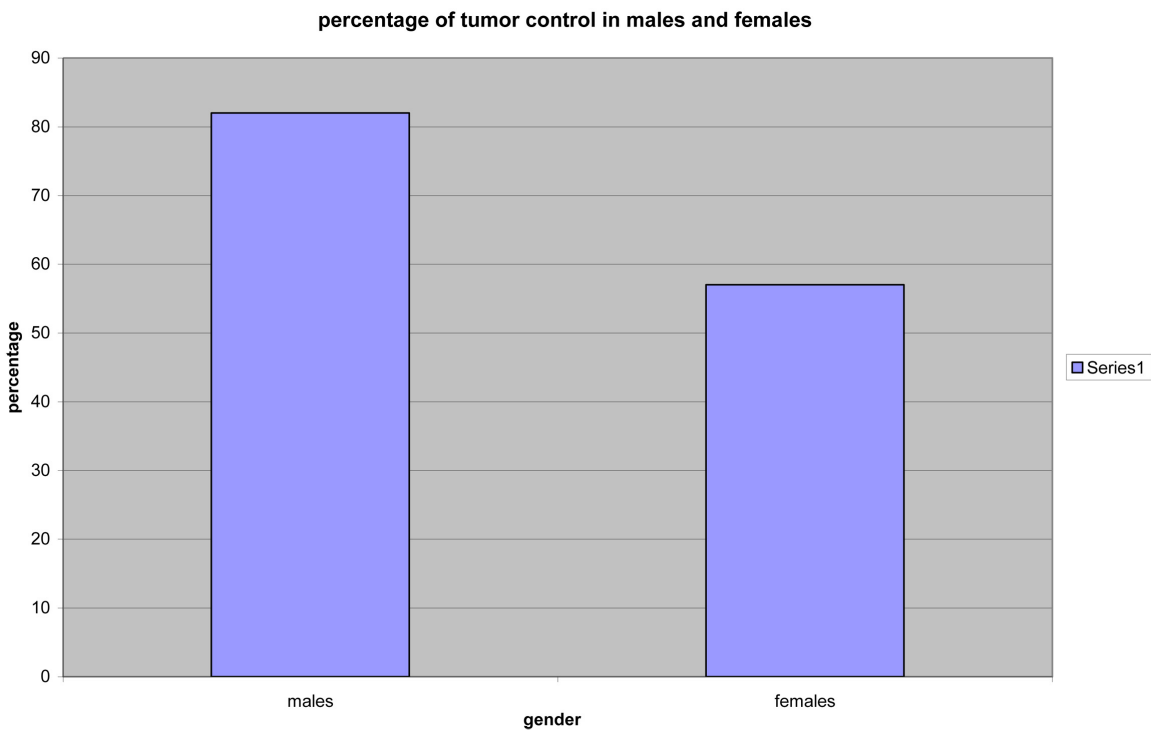

Figure 8. Differences between males and females in tumor control.

Table 1. Follow up of the residual mass and differences between males and females.

\begin{tabular}{|c|c|c|c|c|c|c|c|c|c|c|c|c|}
\hline & \multicolumn{3}{|c|}{$\begin{array}{l}\text { Complete } \\
\text { disappearance of } \\
\text { residual mass }\end{array}$} & \multicolumn{3}{|c|}{$\begin{array}{l}\text { Reduction of the size } \\
\text { of residual mass }\end{array}$} & \multicolumn{3}{|c|}{$\begin{array}{c}\text { The residual mass } \\
\text { unchanged }\end{array}$} & \multicolumn{3}{|c|}{$\begin{array}{c}\text { Increase in size the } \\
\text { residual mass }\end{array}$} \\
\hline & total & male & female & total & male & female & total & male & female & total & male & female \\
\hline $\begin{array}{l}\text { After } 6 \\
\text { months }\end{array}$ & 0 & 0 & 0 & 11 & 9 & 2 & 13 & 0 & 13 & 8 & 2 & 6 \\
\hline $\begin{array}{l}\text { After } 1 \\
\text { year }\end{array}$ & 0 & 0 & 0 & 17 & 9 & 8 & 7 & 0 & 7 & 8 & 2 & 6 \\
\hline $\begin{array}{l}\text { After } 2 \\
\text { years }\end{array}$ & 7 & 7 & 0 & 10 & 2 & 8 & 4 & 0 & 4 & 11 & 2 & 9 \\
\hline
\end{tabular}

$35.5 \%$ of the patients and the rest of the patients had residual mass. Therefore, additional postoperative therapy is still required for those residual NFPA. Radiotherapy is reported to have a role in decreasing the re growth rate of the residual masses [11]. Although Boelaert and Gittoes [12] reported that pituitary radiotherapy may be less hazardous than was originally though, still this is not without an extra cost of side effects like hypopitutarism, neurocognitive dysfunction and cerebrovascular disease besides the rare occurrence of postradia- 
tion secondary intracranial tumor [2]. Prolactinomas have a high level of dopamine 2 receptors and dopamine agonists (DA) are very effective in reducing tumor size and hormone secretion of prolactinoma. NFPAs have varying levels of dopamine receptors [2]. Bromocriptine is a potent agonist at dopamine D2 and at various serotonin receptors [9]. These open the door for finding an additional more safer medical treatment for NFPA. DA was found to have a role in controlling postoperative residual in those tumors. However, no placebo-controlled long-term studies are available to suggest the use of DA in NFPA [2]. 66\% of our patients had tumor control after two years treatment with dopamine agonist with $22 \%$ of the studied patients had complete disappearance of the mass and $34 \%$ of patients failed to respond to bromocriptin. Good response to DA was observed more in males as all our patients (100\%) that totally cured and had no residual mass during follow up were males and $20 \%$ of patients that had tumor reduction were males. Cooper and Greenman [13] reported the largest series of NFPT patients who were treated with DA. In one of the groups that they studied, fifty five patients received preventive DA treatment and twenty four patients received treatment after tumor growth. With preventive treatment $87 \%$ achieved tumor control. While with secondary treatment, 58\% achieved tumor control. Barrow et al. [14] found that Bromocriptine induced tumor growth stabilization in 75 of 84 patients (89\%) with NFPAs as measured on CT scan. Vieira Neto et al. [10] studied 23 patients with post operative residual tumor. $25 \%$ tumor volume reduction was seen on MRI in some of their patients after cabergoline therapy. On the other hand Dekkers et al. [15] reported that spontaneous reduction of tumor size occurred in $29 \%$ of their patients and thus they suggest that just observation of some selected cases of NFPA may be an option for management provided there are no compressive signs as visual affection or hypopituitarism.

\section{Conclusion}

Bromocriptine (DA drug) can play a role in reducing the size or preventing the re-growth of non-functioning pituitary adenoma after surgical debulking. Males showed noticeable response comparing to females. Its regular use might limit the need for surgery in this type of tumor. Further studies with large number of patients are highly recommended.

\section{Conflicts of Interest}

The authors declare no conflicts of interest regarding the publication of this paper.

\section{References}

[1] Katznelson, L., Alexander, J.M. and Klibanski, A. (1993) Clinically Nonfunctioning Pituitary Adenomas. Journal of Clinical Endocrinology and Metabolism, 76, 1089-1094. https://doi.org/10.1210/jcem.76.5.8496297

[2] Colao, A., Di Somma, C., Pivonello, R., Faggiano, A., Lombardi, G. and Savastano, 
S. (2008) Medical Therapy for Clinically Non-Functioning Pituitary Adenomas. Endocrine-Related Cancer, 15, 905-915. https://doi.org/10.1677/ERC-08-0181

[3] Jaffe, C.A. (2006) Clinically Non-Functioning Pituitary Adenoma. Pituitary, 9, 317-321. https://doi.org/10.1007/s11102-006-0412-9

[4] Colao, A., Cerbone, G., Cappabianca, P., Ferone, D., Alfieri, A., Di Salle, F., Faggiano, A., Merola, B., deDivitiis, E. and Lombardi, G. (1998) Effect of Surgery and Radiotherapy in Visual and Endocrine Function in Nonfunctioning Pituitary Adenomas. Journal of Endocrinological Investigation, 21, 284-290. https://doi.org/10.1007/BF03350330

[5] Boelaert, K. and Gittoes, N.J. (2001) Radiotherapy for Nonfunctioning Pituitary Adenomas. European Journal of Endocrinology, 144, 569-575. https://doi.org/10.1530/eje.0.1440569

[6] Gittoes, N.J. (2003) Radiotherapy for Non-Functioning Pituitary Tumours: When and under What Circumstances? Pituitary, 6, 103-108. https://doi.org/10.1023/B:PITU.0000004801.95086.e2

[7] Colao, A., Di Sarno, A., Marzullo, P., Di Somma, C., Cerbone, G., Landi, M.L., Faggiano, A., Merola, B. and Lombardi, G. (2000) New Medical Approaches in Pituitary Adenomas. Hormone Research, 53, 76-87. https://doi.org/10.1159/000023539

[8] Rocheville, M., Lange, D.C., Kumar, U., Patel, S.C., Patel, R.C. and Patel, Y.C. (2000) Receptors for Dopamine and Somatostatin: Formation of Hetero-Oligomers with Enhanced Functional Activity. Science, 288, 154-157.

https://doi.org/10.1126/science.288.5463.154

[9] Walter, S. and Corey, E.J. (2005) Drug Discovery: A History. John Wiley \& Sons, Hoboken, 352. https://books.google.com/books?id=Cb6BOkjK4C\&pg=PA352

[10] Vieira Neto, I., Wildenberg, L.E., Moraes, A.B., Collin, L.M., Kasuki, I., Marques, N.V., et al. (2015) Dopamine: Receptor Subtype 2 Expression Profile in Non Functioning Pituitary Adenomas and in Vivo Response to Cabergoline Therapy. Clinical Endocrinology, 82, 739-746. https://doi.org/10.1111/cen.12684

[11] Ferrante, E., Ferraroni, M., Castrignano, T., Menicatti, L., Anagni, M., Reimondo, G., Del Monte, P., Bernasconi, D., Loli, P., Faustini-Fustini, M., et al. (2006) Non-Functioning Pituitary Adenoma Database: A Useful Resource to Improve the Clinical Management of Pituitary Tumours. European Journal of Endocrinology, 155, 823-829. https://doi.org/10.1530/eje.1.02298

[12] Boelaert, K. and Gittoes, N.J.L. (2001) Radiotherapy for Non-Functioning Pituitary Adenomas. European Journal of Endocrinology, 144, 569-575. https://doi.org/10.1530/eje.0.1440569

[13] Cooper, O. and Greenman, Y. (2018) Dopamine Agonists for Pituitary Adenomas Pituitary Endocrinology, Section in Journal Frontiers of Endocrinolgy 21st August.

[14] Barrow, D.L., Tindall, G.T., Kovacs, K., Thorner, M.O., Horvath, E. and Hoffman, J.C. (1984) Clinical and Pathological Effects of Bromocriptine on Prolactin Secretion and Other Pituitary Tumour. Journal of Neurosurgery, 60, 1-7. https://doi.org/10.3171/jns.1984.60.1.0001

[15] Dekkers, O.M., Hammer, S., de Keizer, R.J., Roelfsema, F., Schutte, P.J., Smit, J.W., Romijn, J.A. and Pereira, A.M. (2007) The Natural Course of Non-Functioning Pituitary Macroadenomas. European Journal of Endocrinology, 156, 217-224. https://doi.org/10.1530/eje.1.02334 